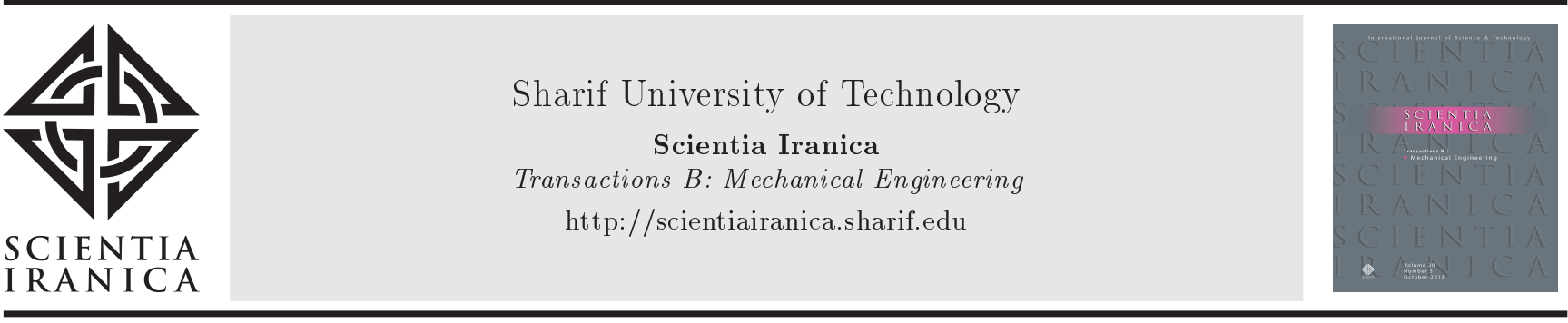

\title{
Influence of tool material on forces, temperature, and surface quality of Ti-15333 alloy in CT and UAT
}

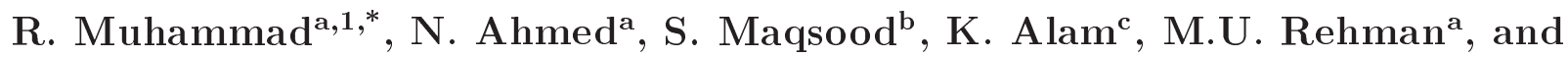 \\ V.V. Silberschmidt ${ }^{\mathrm{d}}$
}

a. Department of Mechanical Engineering, CECOS University of IT \& Emerging Sciences, Peshawar, KPK, Pakistan.

b. Faculty of Industrial Engineering, UET Peshawar Jalozai Campus, Pakistan.

c. Department of Mechanical and Industrial Engineering, Sultan Qaboos University, Musqat, Oman.

d. Wolfson School of Mechanical, Electrical and Manufacturing Engineering, Loughborough University, Loughborough, Leicestershire LE11 $3 T U, U K$.

Received 1 May 2017; received in revised form 10 January 2018; accepted 7 July 2018

KEYWORDS
Tool wear;
Surface roughness;
Machining;
Cutting forces;
Temperature in
process zone;
Ti-alloys.

\section{Introduction}

In recent decades, machining of the alloys has always been a subject of interest in the power-generation, chemical, aerospace, and biomedical industries, which has been mainly focused on nickel and titanium-

1. Present address: Department of Mechanical Engineering, University of Bahrain, P.O. Box 32038, Bahrain.

*. Corresponding author.

E-mail addresses: R.Muhammad@cecos.edu.pk, and R.Muhammad@outlook.com (R. Muhammad).

doi: $10.24200 /$ sci. 2018.20692

\begin{abstract}
Ultrasonically Assisted Turning (UAT) is a progressive machining method in which vibration is applied to the cutting insert in the direction of the cutting tool velocity to reduce the cutting forces significantly and increase the surface finish noticeably. However, the key question about the tool damage caused by the vibration and its effect on the cutting forces, surface roughness, and process zone temperature is still unknown in UAT. This paper conducts an experimental analysis of the effect of a worn tool in UAT and Conventional-Turning (CT) of $\beta$-Ti-15V-3Al-3Cr-3Sn (Ti-15333) alloy on the surface quality of a machined surface, temperature of the process zone, and cutting forces using KC5510 (PVD TiAlN) and CP500 (PVD (Ti,Al)N-TiN) cutting inserts. In UAT, the tool edge damages in CP500 inserts increased with tested machining time, which resulted in the growth of $8 \mathrm{~N}$ and $10 \mathrm{~N}$ in tangential force component in CT and UAT, respectively. Similarly, with the progression of tool edge damage, growth rates of $1.7 \%$ and $9.3 \%$ in the process zone temperature were observed in CT and UAT, respectively. The surface roughness results revealed a gradual degradation with machining time; however, the results of UAT with a worn tool were significantly better than those of CT with a virgin tool.

(C) 2019 Sharif University of Technology. All rights reserved.
\end{abstract}

based alloys [1]. The mediocre machinability of $\mathrm{Ti}$ alloys using conventional-machining-processes is the main disadvantage due to its high strength and lower thermal conductivity. The high level of cutting forces and concentrated temperature at the tool-workpiece interaction zone resulting in diminutive tool life and, hence, poor quality finish of machined components.

With considerable advances in technology, new advanced alloys such as Ti15Zr12Nb and Ti6Al2Sn 4Zr6Mo have been introduced on the basis of strength and resistance to corrosion. However, the main problem associated with those materials is its machinability with conventional machining processes. The 
Table 1. Specifications of cutting inserts.

\begin{tabular}{lcc}
\hline \multicolumn{1}{c}{ Specification } & CP500 & KC5510 \\
\hline Manufacturer & SECO & KENNAMETAL \\
Tool part number & DNMG 150608 MF1 CP500 & DNMG 150608 KC5510 \\
Insert material & Micro-grained tungsten carbide & $\begin{array}{c}\text { Fine-grained tungsten } \\
\text { carbide 6\% cobalt substrate }\end{array}$ \\
Coating material & Conventional PVD $(\mathrm{Ti}, \mathrm{Al})$ N-TiN & Advanced PVD TiAlN \\
Tool nose radius, $r_{c}(\mathrm{~mm})$ & 0.8 & 0.8 \\
Nose angle $\left(^{\circ}\right)$ & 55 & 55 \\
Cutting edge radius $(\mu \mathrm{m})$ & 25 & 25 \\
Rake angle & $14^{\circ} 6^{\prime}$ & $14^{\circ} 6^{\prime}$ \\
Chamfer angle $\left(^{\circ}\right)$ & 0 & 0 \\
\hline
\end{tabular}

high contact pressure and process zone temperature result in short tool life and poor surface quality [25]. Numerous efforts have been made to enhance the machining of these hard-to-cut alloys using advanced coating techniques used in cutting inserts [2,3,6], new tool materials [7], conventional/cryogenic coolants [811], assisted/hybrid machining processes [12-14], and internal processes, e.g., alloy modification without significant changes in material properties $[15,16]$.

Among many, Ultrasonically Assisted Turning (UAT) is one of the developed processes that has shown significant improvement in the machining of hard-tocut alloys [15,17-28]. UAT transforms a continuous cutting process into a transient one by the superimposition of ultrasonic-vibration on the cutting insert, resulting in an intermittent contact between them and a machined workpiece. This technique has shown a $50 \%$ improvement in surface quality and a $65 \%$ decline in cutting forces in the machining of $\mathrm{Ti}$ and nickelbased alloys. Most recently, Muhammad et al. [14,2931] introduced a new variant of UAT called Hot Ultrasonically Aanassisted Turning (HUAT), which has shown an added decline in cutting forces and improvement in surface quality. However, no attempt has been made to examine the influence of tool life in either UAT and in HUAT on finished product quality.

Therefore, in the current work, an experimental procedure was adopted to study the influence of tool edge condition on resulted cutting forces, average process zone temperature, and surface quality of machined components using two types of cutting inserts (CP500 and $\mathrm{KC} 5510$ ) as recommended by the tool suppliers for the conventional turning regimes of $\beta$-Ti- $15 \mathrm{~V}-3 \mathrm{Al}-3 \mathrm{Cr}-$ 3Sn (Ti-15333).

\section{Experimental procedures}

\subsection{Cutting inserts and workpiece material}

A $50-\mathrm{mm}$ bar of $\beta$-Ti alloy $(\beta-\mathrm{Ti}-15 \mathrm{~V}-3 \mathrm{Al}-3 \mathrm{Cr}-3 \mathrm{Sn}$ designated as Ti-15333) with a length of $300 \mathrm{~mm}$ was used in CT and UAT tests. Additional details about the studied alloy can be found elsewhere $[15,19]$. CP500 and KC5510 cutting inserts recommended by the manufacturer for $\mathrm{Ti}$ alloys were used in experiments. CP500 cutting inserts are suitable for intermittent cutting, whereas KC5510 is an advanced micro-grain coating insert consisting of $6 \%$ cobalt of substrate material and is recommended for moderate cutting of hard-to-cut materials. The specifications of these inserts are presented in Table 1.

\subsection{Machining}

A universal 300 Harrison lathe machine was used for CT and UAT of Ti15333 alloy. The tool post of the lathe machine was reformed to support a piezoelectric transducer to impose vibrations $(20 \mathrm{kHz}$ of frequency and $10 \mu \mathrm{m}$ of amplitude) on the cutting insert, as shown in Figure 1. The ultrasonic system developed at Loughborough University, UK is an open-loop system and is optimized for the above ultrasonic parameters. The maximum force reduction and improvement in surface finish are reported for $\mathrm{Ti}$ - and Ni-based alloys $[17,18,22,32]$. A four-jaw chuck was used to clamp the workpiece on the lathe machine. A mechanical dial gauge was used to adjust the eccentricity of the workpiece material. The following cutting conditions were employed in this investigation:

- Cutting speeds (m/min): 10 and 30;

- Feed rate (mm/rev): 0.1;

- Depth-of-cut (mm): 0.3;

- Dry cutting;

- Time interval, $t$ (s): 100, 300, 500, and 700 .

All experiments were conducted four times to achieve realistic statistics for the experimentally achieved data.

A Kistler dynamo-meter was used to capture cutting forces in real time. The output signal from the dynamo-meter passed through an amplifier followed by a picoscope to get a digital format of all cutting forces. Later on, a Matlab program was used to calculate the average cutting forces for all tests. 


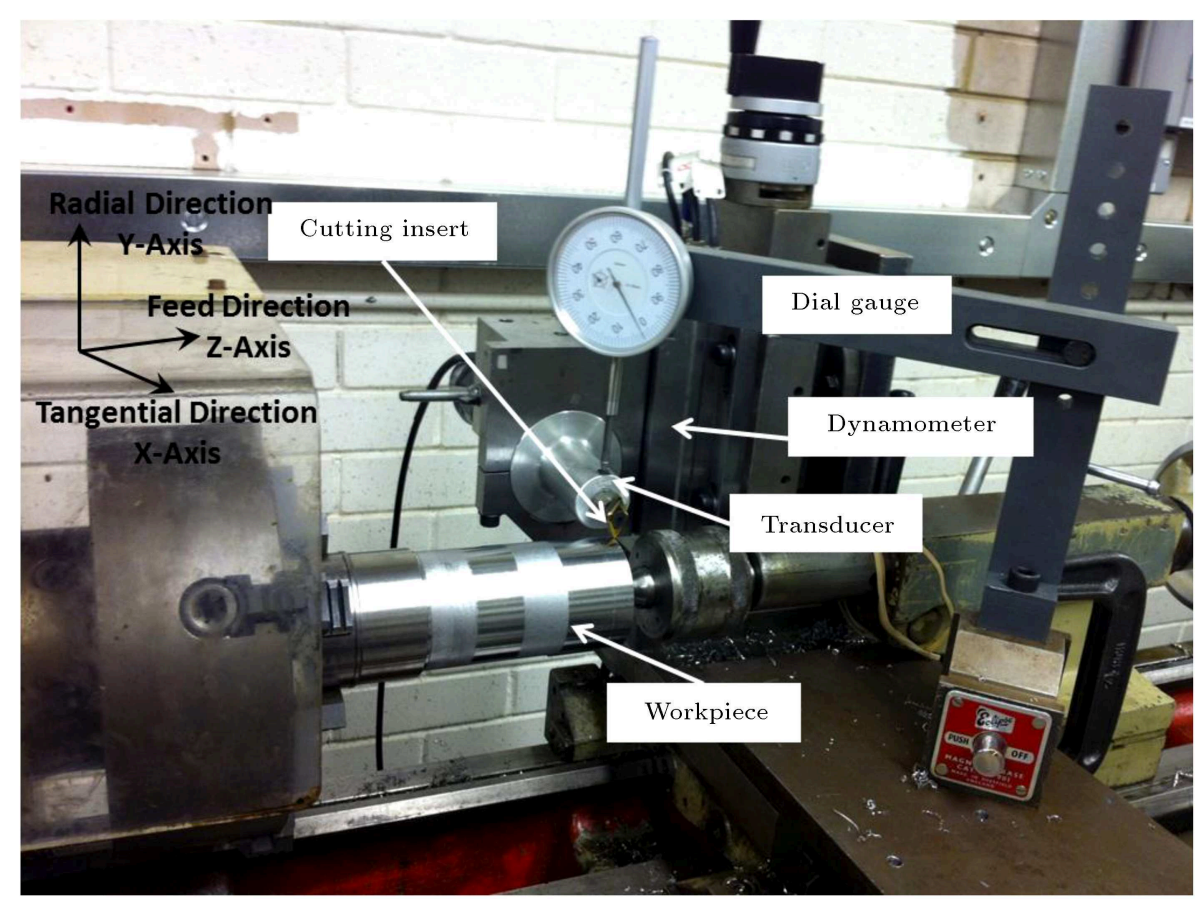

Figure 1. Setup used for CT and UAT experimentation.

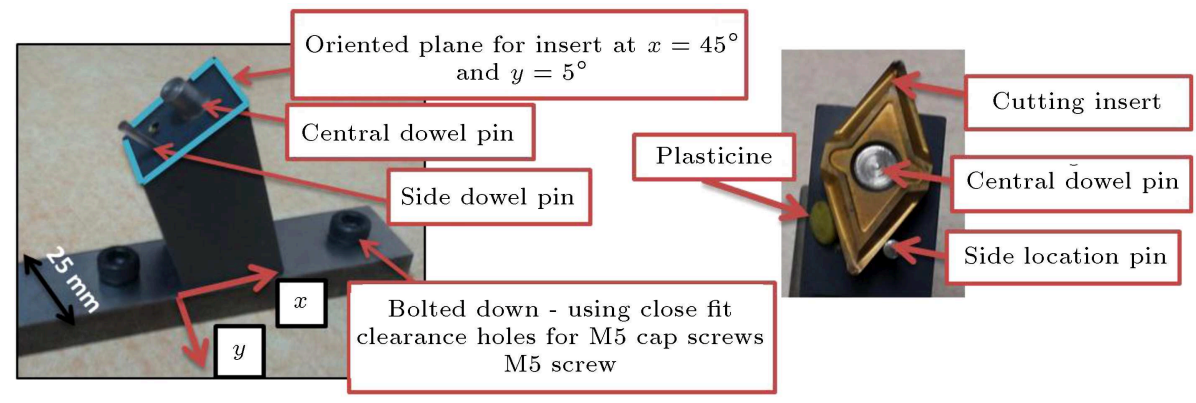

(a)

(b)

Figure 2. (a) Special insert fixture. (b) Cutting insert placed on oriented plane of fixture.

For thermal measurements, an FLIR Therma$\mathrm{CAM}^{\mathrm{TM}}$ SC3000 system was used for real-time acquisition. The new stirling-cooled Quantum Well-InfraredPhoton (QWIP) enables the FLIR ThermaCAM ${ }^{\mathrm{TM}}$ system to image the process at lower noise exposure and better image uniformity using the continuous recording mode. Further details of the system can be found in the experiment elsewhere [14].

The surface roughness analysis of machined specimens was carried out using Mitutoyu-Surftest-211 equipment. A standard calibrated block available with the instrument was used to calibrate the system before considering surface roughness reading in experiments. The standard, arithmetic mean surface-roughness parameter $(R a)$ was calculated. The $R a$ measurements were taken at different locations of the specimens at specified time intervals as mentioned above, and each test was repeated at least four times to achieve good statistical data for $R a$.
Similarly, a 3D optical measurement system, infinite-focus by Alicona, was used for tool wear analysis. A special tool fixture was designed to ensure accurate positioning of the cutting insert in various stages of its life in experimentation (Figure 2(a)). The orientation of the plane of the fixture (Figure 2(b)) was achieved through a series of trials, carried out on the Alicona infinite-focus system to get a good-quality scan of the inserts. A $5 \times$ objective of the system was used because of its larger field of view compared to a $10 \times$ objective, and it was found that it was fully capable to cope with the wear-prone region even when the wear progress occurred along the flank face of the insert. A step-wise procedure was used to carry out tool wear analysis in both CT and UAT. Initially, the inserts were used to perform CT and UAT on the Ti-15333 for selected time intervals. An ultrasonic bath was given to the inserts after machining to remove unwanted solid, semi-solid or liquid contaminants, which can include 
metallic and non-metallic debris, chips, dirt particles, and other elements from the surface of the insert. A cleaning procedure with pressurized air was used to ensure removal of any dirt particles to achieve a more accurate scan of the cutting insert.

The Alicona machine software enjoys an in-built feature known as difference measurement, which is dedicated to volume measurement. This feature was used to calculate the amount of volume reduction for the cutting inserts after machining by comparing a scan of the virgin sample (a reference scan) with that of the used insert. All experiments for UAT and CT were conducted on the in-house state-of-the-art experimental setup available at Loughborough University, UK. Additional details about the experimental setup can be found elsewhere $[15,19]$. The experiments were repeated three times for each cutting condition. For CP500, the spread of data was huge because one insert, each at both cutting speeds, does not fail due to BUE formation. However, the rest of the data are reasonably in good shape and the results are repeatable in both CT and UAT.

\section{Results and discussions}

\subsection{Tool wear}

The tool wear analysis was carried out using InfiniteFocus by Alicona. A reduction in volume at the cutting edge was achieved in both $\mathrm{CT}$ and UAT at the tested cutting parameters, as shown in Figures 3 and 4. A volume reduction of $1.6 \times 10^{6} \mu \mathrm{m}^{3}$ in CP500 inserts was calculated in $\mathrm{CT}$ at $100 \mathrm{~s}$. The inserts experienced a high level of cutting forces, and process zone temperature after making initial contact with the workpiece materials resulted in a rapid reduction in the volume of the insert cutting edge. The progress in volume reduction was amplified with an increase in machining time, and a further reduction of $0.15 \times 10^{6} \mu \mathrm{m}^{3}$ in volume of the cutting edge was observed at $300 \mathrm{~s}$. Similarly, a total reduction of $1.9 \times 10^{6} \mu \mathrm{m}^{3}$ in tool edge

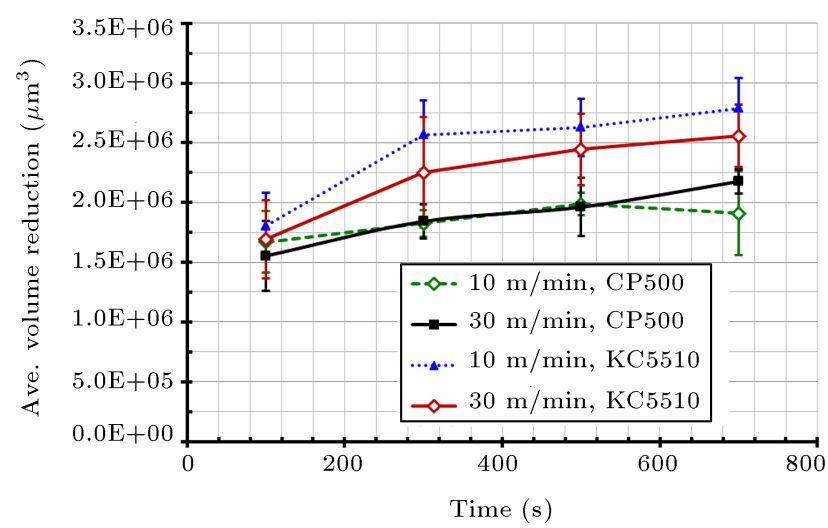

Figure 3. Volume reduction in cutting inserts at various time intervals in CT.

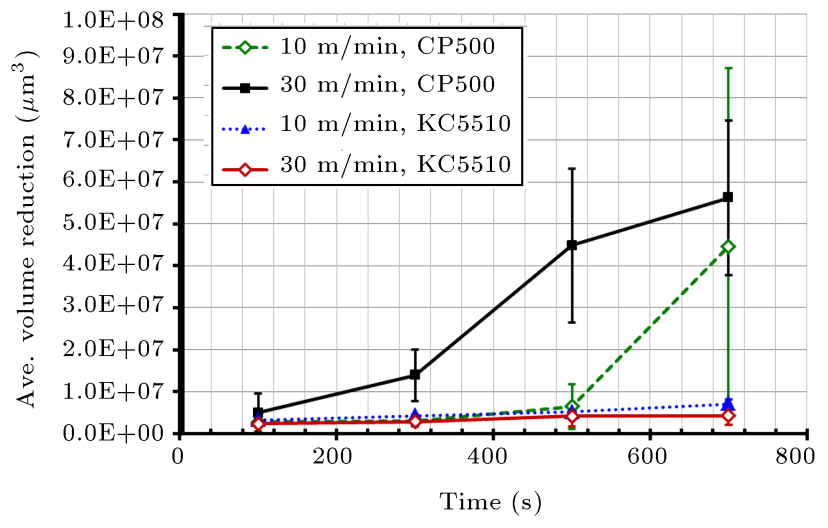

Figure 4. Material removal progress in CT in KC5510 insert [35].

volume was measured after $700 \mathrm{~s}$ of machining of Ti15333. A better performance was shown by the CP500 inserts in $\mathrm{CT}$ at $30 \mathrm{~m} / \mathrm{min}$. An average reduction of $1.5 \times 10^{6} \mu \mathrm{m}^{3}$ and $1.8 \times 10^{6} \mu \mathrm{m}^{3}$ in tool edge volume was observed at $100 \mathrm{~s}$ and $300 \mathrm{~s}$, respectively, when compared to the virgin insert. The progression in tool damage continued with machining time, and average reductions of $1.9 \times 10^{6} \mu \mathrm{m}^{3}$ and $2.1 \times 10^{6} \mu \mathrm{m}^{3}$ were calculated at $500 \mathrm{~s}$ and $700 \mathrm{~s}$, respectively. The level of volume reduction at a tested time interval in CP500 inserts at $10 \mathrm{~m} / \mathrm{min}$ and $30 \mathrm{~m} / \mathrm{min}$ was almost the same with some minor variation (see Figure 5).

Similarly, the performance of KC5510 cutting inserts was also evaluated at the studied cutting parameters. An average volume reduction of $1.8 \times 10^{6} \mu \mathrm{m}^{3}$ and $1.6 \times 10^{6} \mu \mathrm{m}^{3}$ at $100 \mathrm{~s}$ was calculated at $10 \mathrm{~m} / \mathrm{min}$ and $30 \mathrm{~m} / \mathrm{min}$ cutting speeds, respectively. An increase in volume reduction was observed with machining time, and the average decrease of $2.5 \times 10^{6}{\mu \mathrm{m}^{3}}^{3}, 2.6 \times$ $10^{6} \mu \mathrm{m}^{3}$, and $2.7 \times 10^{6} \mu \mathrm{m}^{3}$ was measured at $300 \mathrm{~s}$, $500 \mathrm{~s}$, and $700 \mathrm{~s}$, respectively, at $10 \mathrm{~m} / \mathrm{min}$. On the other hand, at $30 \mathrm{~m} / \mathrm{min}$, a reduction in volume of $2.2 \times 10^{6} \mu \mathrm{m}^{3}, 2.4 \times 10^{6} \mu \mathrm{m}^{3}$, and $2.5 \times 10^{6} \mu \mathrm{m}^{3}$ was calculated at $300 \mathrm{~s}, 500 \mathrm{~s}$, and $700 \mathrm{~s}$, respectively.

The CP500 and KC5510 inserts are designed for CT that have shown better performance at both cutting speeds. However, the volume removed at both cutting speeds in CP500 cutting inserts was lower than that in KC5510 cutting inserts (see Figure 3). The level of tool edge volume lost by CP500 inserts at the tested cutting speeds was approximately the same with some minor fluctuations. On the contrary, in KC5510 cutting inserts, the material removal rate was reduced with an increase in cutting speeds from $10 \mathrm{~m} / \mathrm{min}$ to $30 \mathrm{~m} / \mathrm{min}$. The substrate material of these inserts contained small contents of Cobalt particles, providing them with a tougher and finer grain structure suitable for high-load applications.

Transition to vibro-impact machining in the UAT regime affected the character of tool life in terms of 


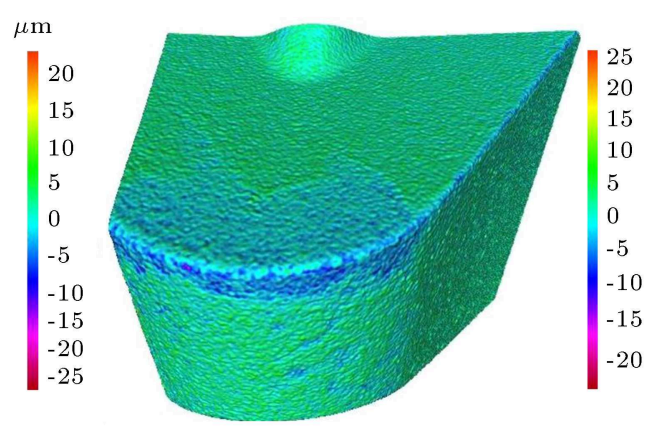

$t_{m}=100 \mathrm{~s}, d_{m}=17 \mathrm{~m}$

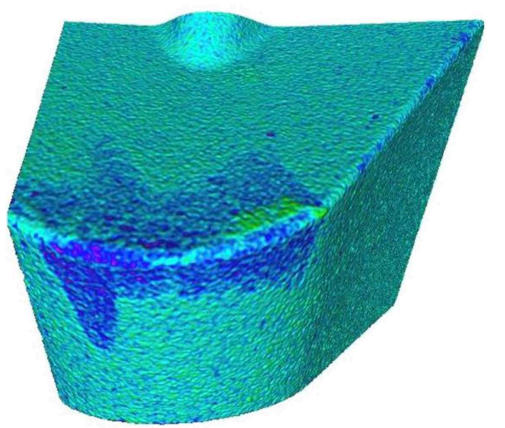

$t_{m}=700 \mathrm{~s}, d_{m}=117 \mathrm{~m}$

Figure 5. Volume reduction in cutting inserts at various time intervals in UAT.
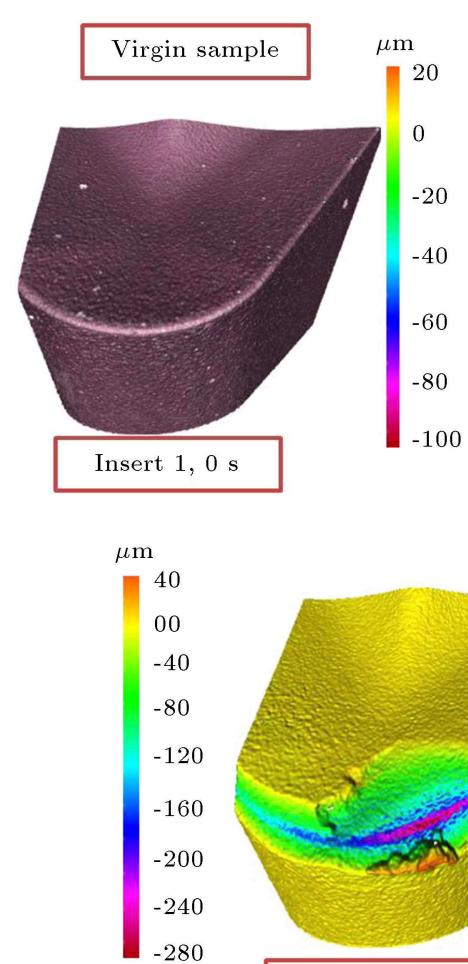
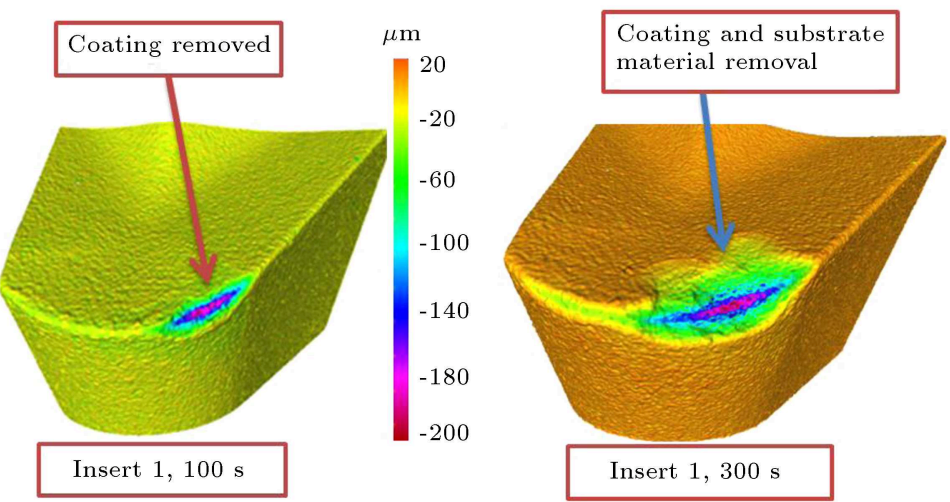

Insert $1,300 \mathrm{~s}$

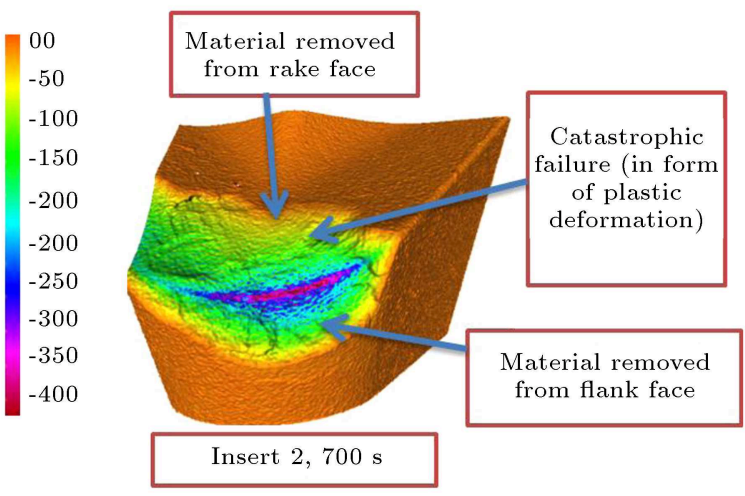

Figure 6. Material removal progress to catastrophic failure in CP500 cutting insert in UAT at a cutting speed of $10 \mathrm{~m} / \mathrm{min}$ in various stages [35].

volume reduction. The decay in average volume of tested cutting inserts in UAT is shown in Figure 4. The levels of volume reduction for both cutting inserts in UAT were comparatively higher than those in CT. At $100 \mathrm{~s}$, the level of volume lost by the CP500 insert was $2.7 \times 10^{6} \mu \mathrm{m}^{3}$. The volume reduction increased with an increase in time, and average reduction rates of $3.0 \times 10^{6} \mu \mathrm{m}^{3}, 6.4 \times 10^{6} \mu \mathrm{m}^{3}$, and $44.5 \times 10^{6} \mu \mathrm{m}^{3}$ were observed at $300 \mathrm{~s}, 500 \mathrm{~s}$, and $700 \mathrm{~s}$, respectively. The rapid failure of the CP500 inserts observed at $700 \mathrm{~s}$ resulted in a rapid increase of volume reduction by a factor of 6 . The decay in volume of one of the tested CP500 inserts is shown in Figure 6 . At $30 \mathrm{~m} / \mathrm{min}$,
CP500 inserts showed better performance up to $100 \mathrm{~s}$, and a reduction of $4.9 \times 10^{6} \mu \mathrm{m}^{3}$ in cutting edge volume was calculated. However, a rapid increase in volume reduction was observed for the subsequent time internals. Reduction rates of $13.8 \times 10^{6} \mu \mathrm{m}^{3}, 44.8 \times$ $10^{6} \mu \mathrm{m}^{3}$, and $56.2 \times 10^{6} \mu \mathrm{m}^{3}$ was calculated at $300 \mathrm{~s}$, $500 \mathrm{~s}$, and $700 \mathrm{~s}$, respectively. The catastrophic failure in CP500 insert in the form of plastic deformation was linked to the substrate composition of CP500 insert, causing significantly lower impact resistance [33].

A reduction of $3.2 \times 10^{6} \mu \mathrm{m}^{3}$ in KC5510 volume was observed at $100 \mathrm{~s}$ in UAT at a cutting speed of $10 \mathrm{~m} / \mathrm{min}$. With an increase in machining time, further 


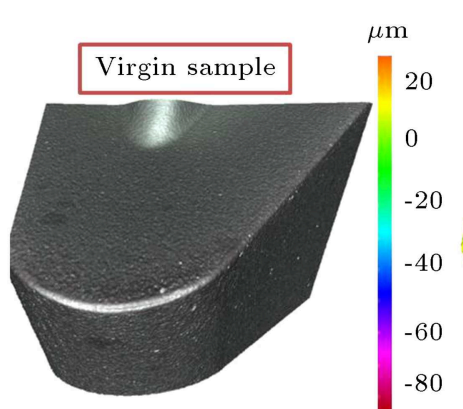

$(0 \mathrm{~s})$

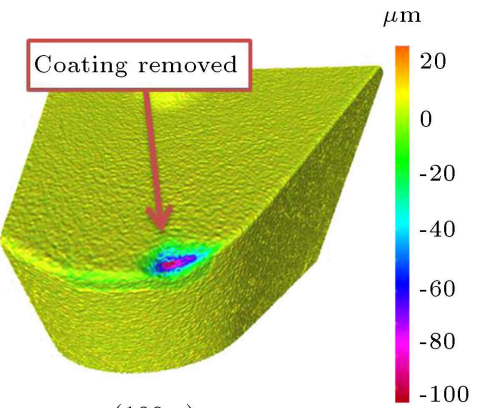

$(100 \mathrm{~s})$

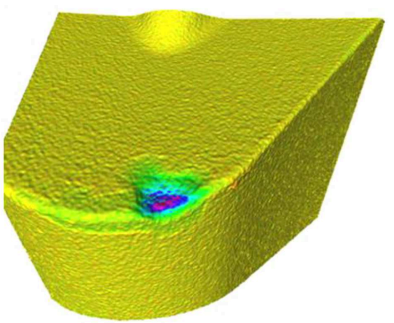

$(300 \mathrm{~s})$
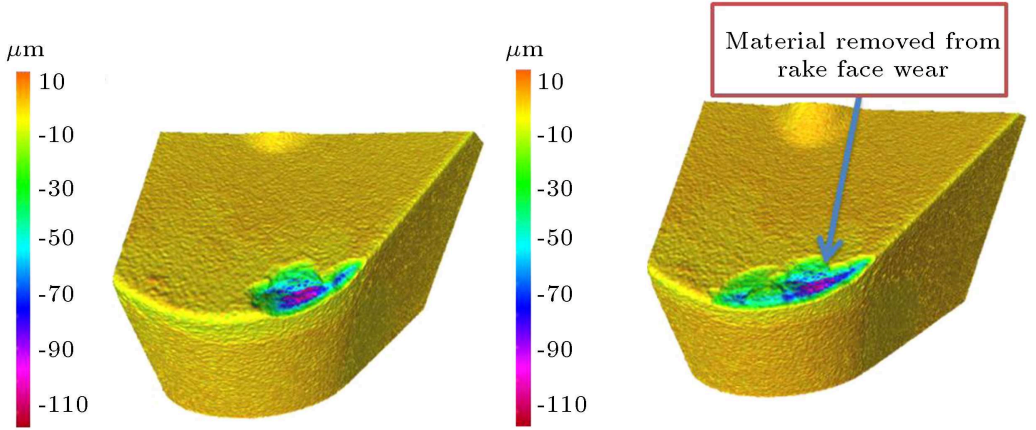

$(700 \mathrm{~s})$

Figure 7. Material removal progress of insert KC5510 in UAT at a cutting speed of $10 \mathrm{~m} / \mathrm{min}$ in various stages [35].

increases of nearly $1.0 \times 10^{6} \mu \mathrm{m}^{3}, 0.8 \times 10^{6} \mu \mathrm{m}^{3}$, and $1.9 \times 10^{6} \mu \mathrm{m}^{3}$ were reported at $300 \mathrm{~s}, 500 \mathrm{~s}$, and $700 \mathrm{~s}$, respectively. Similarly, these inserts demonstrated even better performance at $30 \mathrm{~m} / \mathrm{min}$ in UAT. Initially, a reduction of $2.3 \times 10^{6} \mu^{3}$ in tool edge volume was calculated at $100 \mathrm{~s}$. However, the decay in tool edge volume increased with an increase in time, and the total decreases of $2.8 \times 10^{6} \mu \mathrm{m}^{3}, 4.1 \times 10^{6} \mu \mathrm{m}^{3}$, and $4.2 \times 10^{6} \mu^{3}$ were calculated at $300 \mathrm{~s}, 500 \mathrm{~s}$, and $700 \mathrm{~s}$, respectively. This extremely positive toolwear behavior of KC5510 insert in UAT, as compared to that of CP500, can be explained by its substrate composition [33]. The material removal development in the KC5510 cutting insert is presented in Figure 7.

Based on a comparison of the material removal progress in the two studied inserts in CT and UAT, a shorter tool life for CP500 inserts was observed in UAT when compared to KC5510. Although the coating was eventually removed in both inserts, the substrate of insert KC5510 demonstrated significantly greater resistance to localized plastic deformation and to failure once the physical damage began, showing better performance in UAT $[33,34]$.

\subsection{Cutting forces}

The results obtained from experimentation at $10 \mathrm{~m} / \mathrm{min}$ demonstrated that a substantial drop of approximately $75 \%$ was achieved in $F_{t}$ in UAT, as shown in Figures 8 and 9. Similarly, a considerable decline of approximately $70 \%$ in $F_{r}$ was also recorded using both inserts. The superposition of vibrations on

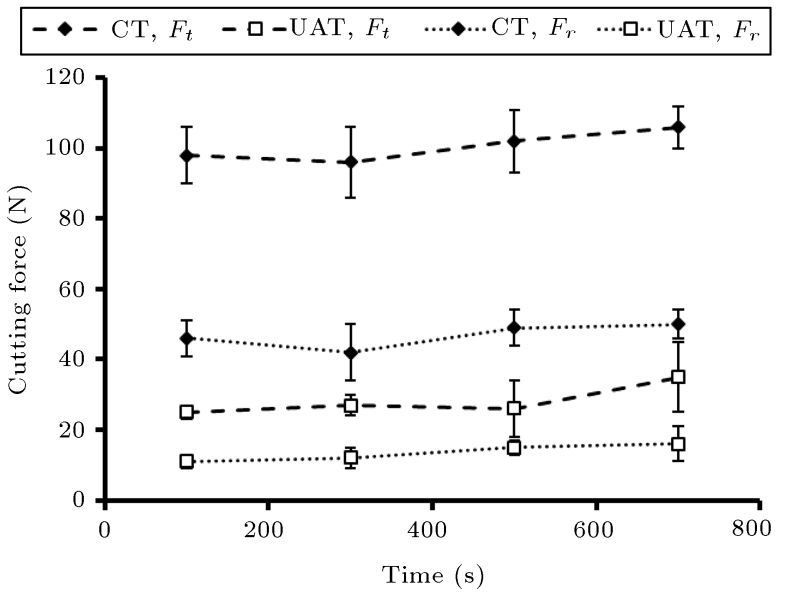

Figure 8. The average level of $F_{t}$ and $F_{r}$ observed in UAT and CT of Ti-15333 using CP500 cutting inserts and $V=10 \mathrm{~m} / \mathrm{min}$.

the cutting insert induces separation of the cutting tool from the chip in one complete vibration cycle, leading to a reduction in average force levels [18]. The tool comes into contact with the chip in the penetration stage, which is the reason why an almost peak level of the cutting forces was observed in $\mathrm{CT}$, where the level of forces started to decline and reached the zero level during the retraction stage. As a result, a substantial drop in average $F_{t}$ and $F_{r}$ was observed in UAT.

The level of $F_{t}$ for both cutting inserts was almost the same due to their similar geometries at 


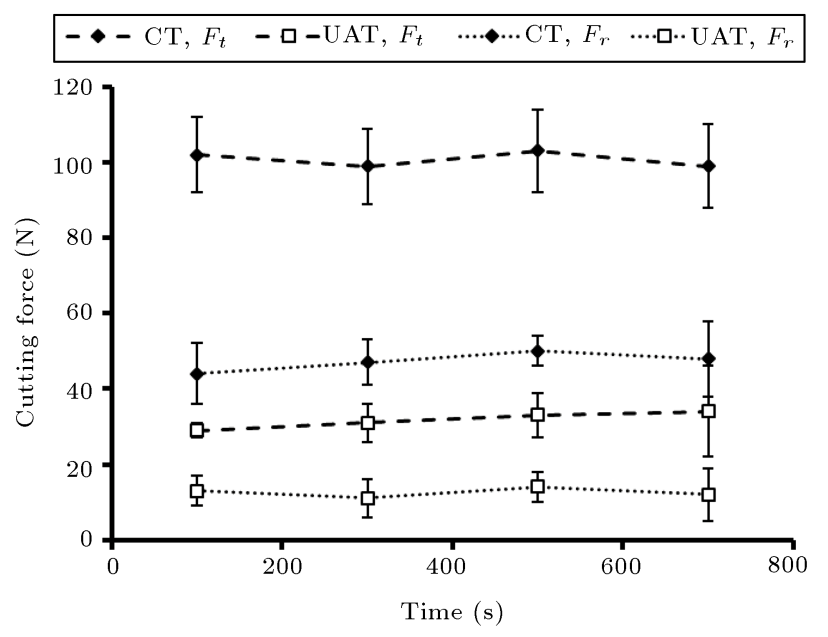

Figure 9. The average level of $F_{t}$ and $F_{r}$ observed in UAT and CT of Ti-15333 using KC5510 cutting inserts and $V=10 \mathrm{~m} / \mathrm{min}$.

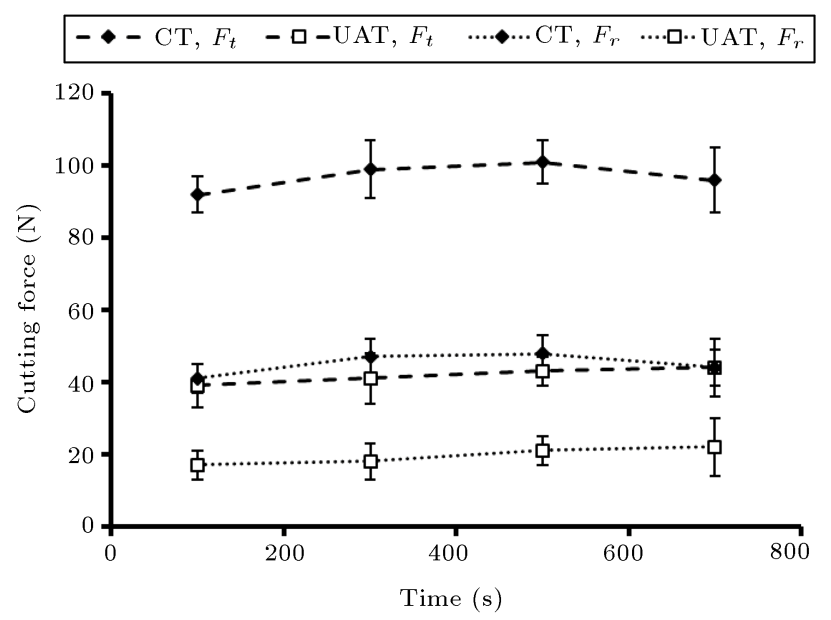

Figure 10. The level of $F_{t}$ and $F_{r}$ observed in UAT and CT of Ti-15333 using CP500 cutting inserts and $V=30 \mathrm{~m} / \mathrm{min}$.

both cutting speeds. In CT, $F_{t}$ of $98 \mathrm{~N}$ and $102 \mathrm{~N}$ was observed at $10 \mathrm{~m} / \mathrm{min}$ using CP500 and KC5510 inserts, respectively. Similarly, $F_{r}$ of $46 \mathrm{~N}$ and $44 \mathrm{~N}$ was observed in CP500 and KC5510, respectively. Minor fluctuations in $F_{t}$ and $F_{r}$ were observed in both inserts with an increase in the machining time. The influence of cutting speed on $F_{t}$ and $F_{r}$ was negligible for both inserts in CT, whereas a gradual growth in the level of $F_{t}$ and $F_{r}$ was observed in UAT with an increase in the cutting speed from $10 \mathrm{~m} / \mathrm{min}$ to $30 \mathrm{~m} / \mathrm{min}$, as shown in Figures 10 and 11. The level of $F_{t}$ increased from $25 \mathrm{~N}$ to $39 \mathrm{~N}$ and from $29 \mathrm{~N}$ to $37 \mathrm{~N}$ using CP500 and KC5510 inserts, respectively. Similarly, a growth of $4 \mathrm{~N}$ and $6 \mathrm{~N}$ was calculated in $F_{r}$ for CP500 and KC5510 inserts, respectively. This observation was expected because, in UAT, the separation of the cutting tool reduced with an increase in cutting speed, resulting in

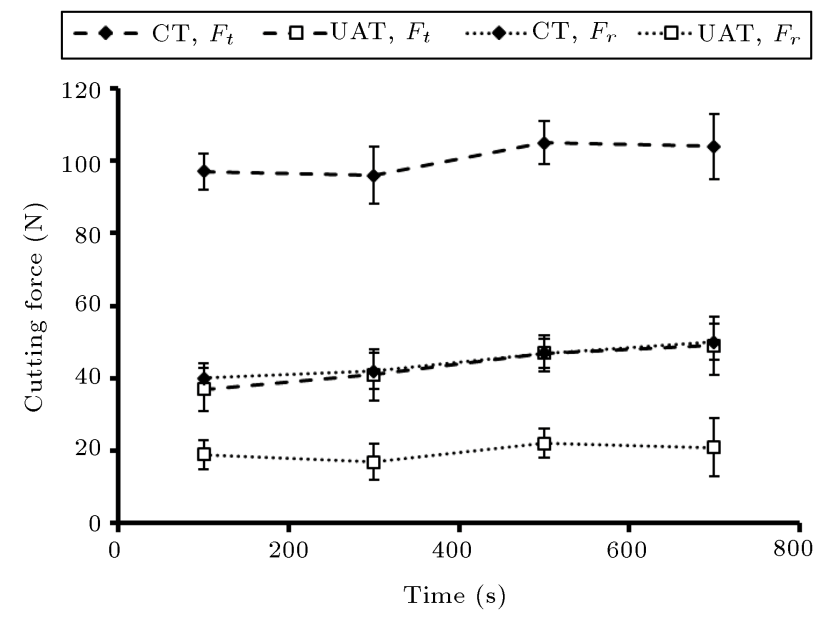

Figure 11. The level of $F_{t}$ and $F_{r}$ observed in UAT and CT of Ti-15333 using KC5510 cutting inserts and $V=30 \mathrm{~m} / \mathrm{min}$.

an increase in the level of $F_{t}$ and $F_{r}$ when compared to those obtained at $10 \mathrm{~m} / \mathrm{min}$ [17-19]. A minor variation (up to a maximum of $12 \mathrm{~N}$ ) in the level of $F_{t}$ and $F_{r}$ was observed with progression of tool edge damage for both inserts in UAT and CT; however, the effect of tool edge damage was not severe in the level of $F_{t}$ and $F_{r}$ in UAT. Hence, the level of $F_{t}$ and $F_{r}$ observed in UAT for both cutting inserts was considerably lower than that observed in CT, besides its poorly short tool life. This demonstrates the importance and significance of UAT in machining high-strength alloys with worn tools.

\subsection{Process zone temperature}

The average process zone temperature in both UAT and CT was also examined experimentally for both inserts, as presented in Figure 12. The calculated temperature levels did not show the actual temperature generated in the tool workpiece interaction region due to the obstacle generated by the chip during process zone temperature recording. Similarly, the problems are associated with aligning the camera at a preferable angle due to the restrictions produced by the machine. Still, the data obtained in the current study presented a good quantitative analysis of UAT and CT in turning of Ti-15333 using CP500 and KC5510 cutting inserts.

The prime cause of heat generated during machining processes is the plastic deformation in the primary and secondary zones of deformation with a minimal contribution of frictional effect (below 10\%) [36]. The experimental results indicate that the average process zone temperatures in CP500 and KC5510 cutting inserts in UAT were higher than those observed in CT. The possible reason is the amount of energy applied to the tool in the form of vibrations, which increased the relative cutting velocity of the inserts in UAT [22].

The measured process zone temperatures in $\mathrm{CT}$ at $10 \mathrm{~m} / \mathrm{min}$ using CP500 and KC5510 inserts were $288^{\circ} \mathrm{C}$ 

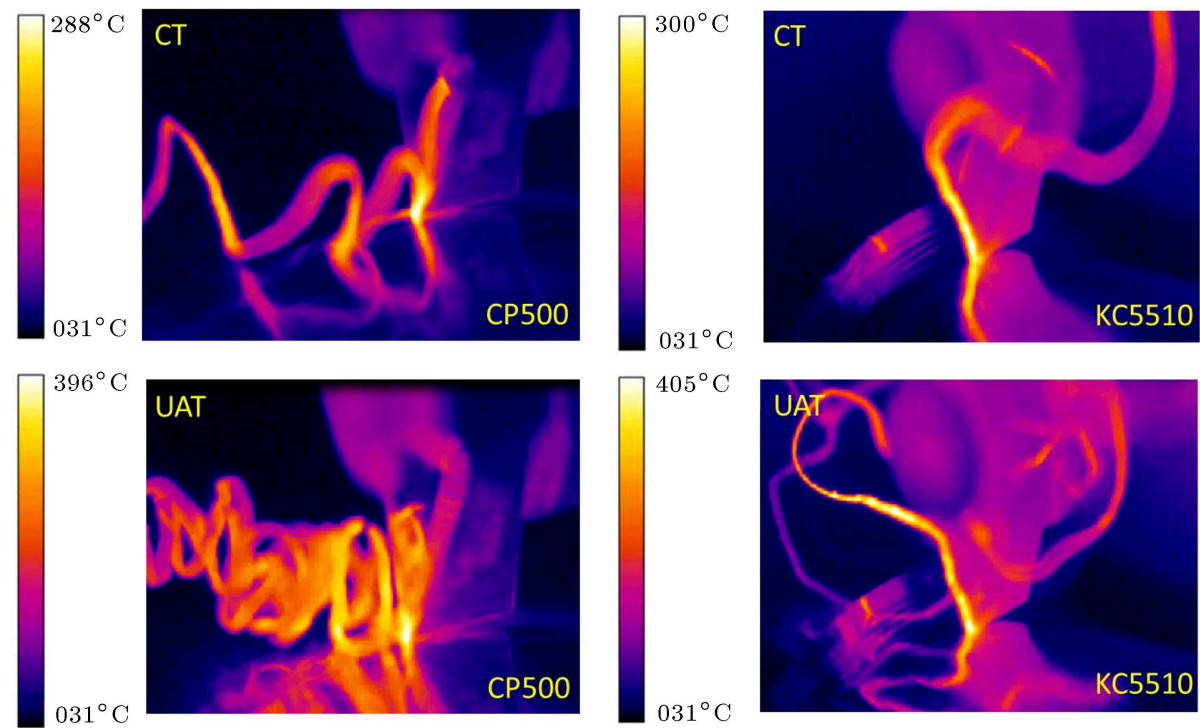

Figure 12. Process zone temperature in UAT and CT for both tools at $100 \mathrm{~s}$ and $V=10 \mathrm{~m} / \mathrm{min}$.

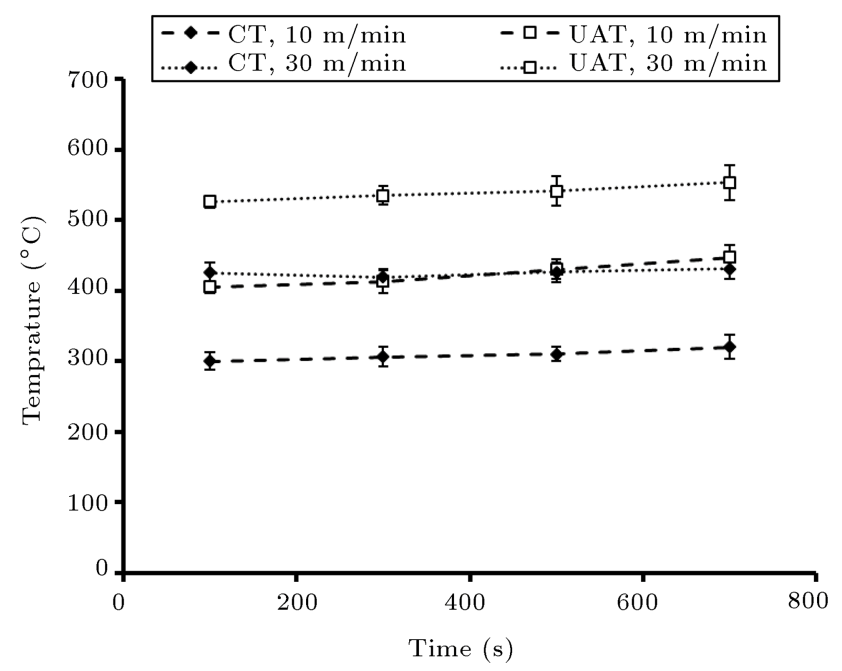

Figure 13. Process zone temperature in UAT and CT at various time intervals using CP500 inserts.

and $300^{\circ} \mathrm{C}$, respectively. In addition, the superposition of vibration on the cutting insert yielded an additional growth of approximately $100^{\circ} \mathrm{C}$ in UAT (see Figures 13 and 14). The levels of process zone temperatures measured in CP500 and KC5510 inserts were $396^{\circ} \mathrm{C}$ and $405^{\circ} \mathrm{C}$, respectively. Furthermore, a noticeable growth in the average process zone temperature was noticed for both inserts with a rise in cutting speed, as expected. The average growth rates of $113^{\circ} \mathrm{C}$ and $125^{\circ} \mathrm{C}$ were observed in CT using CP500 and KC5510 inserts, respectively, when cutting speed increased from $10 \mathrm{~m} / \mathrm{min}$ to $30 \mathrm{~m} / \mathrm{min}$. Similarly, an average increase in the process zone temperature of $109^{\circ} \mathrm{C}$ and $116^{\circ} \mathrm{C}$ was measured in UAT using CP500 and KC5510 inserts, respectively.

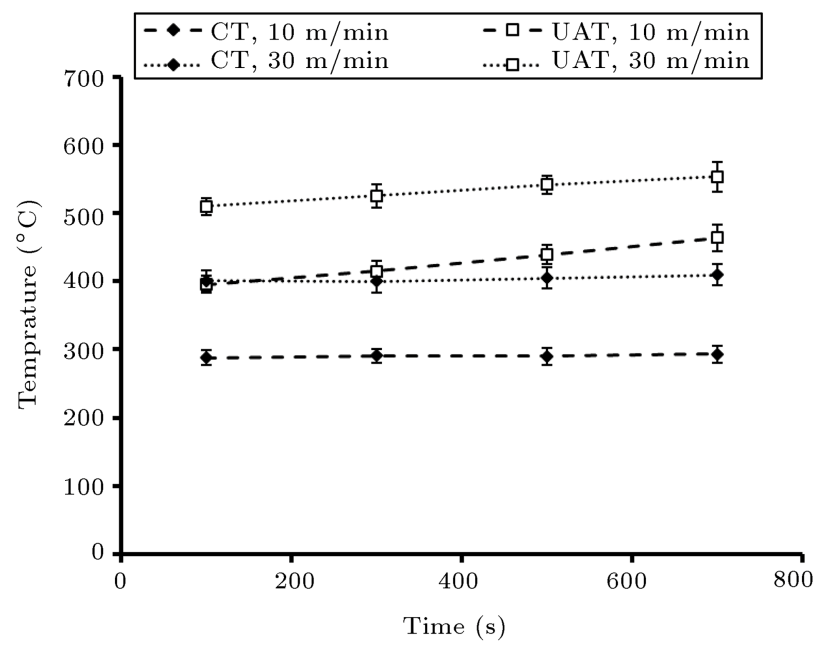

Figure 14. Process zone temperature in UAT and CT at various time intervals using KC5510 inserts.

The cutting edge condition has a marginal influence on the average process zone temperature in the machining of Ti-alloys; in the current study, an increase in the average process zone temperature was noticed with the tool damage progression. In $\mathrm{CT}$, the rise of average process zone temperature was minor for both tools due to lower damage to the insert edge. In CP500 inserts and $10 \mathrm{~m} / \mathrm{min}$, a growth of $5^{\circ} \mathrm{C}$ was measured at $700 \mathrm{~s}$ when compared to the level of temperature observed at $100 \mathrm{~s}$. Similarly, a growth of $20^{\circ} \mathrm{C}$ was achieved at $700 \mathrm{~s}$ in KC5510 inserts. At $30 \mathrm{~m} / \mathrm{min}$, the level of process zone temperature increased from $401^{\circ} \mathrm{C}$ to $410^{\circ} \mathrm{C}$ in $\mathrm{CP} 500$ inserts, whereas, in KCC5510 inserts, an increase of $6^{\circ} \mathrm{C}$ was obtained.

On the contrary, a visible increase in the average process zone temperature was detected in UAT with 
Table 2. The average surface roughness measurement of a machined surface at various time intervals.

\begin{tabular}{|c|c|c|c|c|}
\hline \multicolumn{5}{|c|}{ CP500 cutting insert, $V=10 \mathrm{~m} / \mathrm{min}$} \\
\hline Time & $100 \mathrm{~s}$ & $300 \mathrm{~s}$ & $500 \mathrm{~s}$ & $700 \mathrm{~s}$ \\
\hline Surface roughness & $R a(\mu \mathrm{m})$ & $R a(\mu \mathrm{m})$ & $R a(\mu \mathrm{m})$ & $R a(\mu \mathrm{m})$ \\
\hline $\mathbf{C T}$ & $1.73 \pm 0.31$ & $1.75 \pm 0.20$ & $1.74 \pm 0.21$ & $1.80 \pm 0.30$ \\
\hline UAT & $1.01 \pm 0.11$ & $1.13 \pm 0.21$ & $1.53 \pm 0.31$ & $1.65 \pm 0.41$ \\
\hline \multicolumn{5}{|c|}{ KC5510 cutting insert, $V=10 \mathrm{~m} / \mathrm{min}$} \\
\hline Time & $100 \mathrm{~s}$ & $300 \mathrm{~s}$ & $500 \mathrm{~s}$ & $700 \mathrm{~s}$ \\
\hline Surface roughness & $R a(\mu \mathrm{m})$ & $R a(\mu \mathrm{m})$ & $R a(\mu \mathrm{m})$ & $R a(\mu \mathrm{m})$ \\
\hline $\mathbf{C T}$ & $1.82 \pm 0.61$ & $1.61 \pm 0.31$ & $1.79 \pm 0.42$ & $1.95 \pm 0.52$ \\
\hline UAT & $0.96 \pm 0.32$ & $1.15 \pm 0.29$ & $1.35 \pm 0.31$ & $1.47 \pm 0.26$ \\
\hline \multicolumn{5}{|c|}{ CP500 cutting insert, $V=30 \mathrm{~m} / \mathrm{min}$} \\
\hline Time & $100 \mathrm{~s}$ & $300 \mathrm{~s}$ & $500 \mathrm{~s}$ & $700 \mathrm{~s}$ \\
\hline Surface roughness & $R a(\mu \mathrm{m})$ & $R a(\mu \mathrm{m})$ & $R a(\mu \mathrm{m})$ & $R a(\mu \mathrm{m})$ \\
\hline $\mathbf{C T}$ & $1.09 \pm 0.41$ & $1.00 \pm 0.32$ & $1.16 \pm 0.39$ & $1.31 \pm 0.22$ \\
\hline UAT & $0.82 \pm 0.24$ & $0.91 \pm 0.39$ & $0.99 \pm 0.23$ & $1.19 \pm 0.36$ \\
\hline \multicolumn{5}{|c|}{ KC5510 cutting insert, $V=30 \mathrm{~m} / \mathrm{min}$} \\
\hline Time & $100 \mathrm{~s}$ & $300 \mathrm{~s}$ & $500 \mathrm{~s}$ & $700 \mathrm{~s}$ \\
\hline Surface roughness & $R a(\mu \mathrm{m})$ & $R a(\mu \mathrm{m})$ & $R a(\mu \mathrm{m})$ & $R a(\mu \mathrm{m})$ \\
\hline CT & $1.02 \pm 0.33$ & $1.13 \pm 0.25$ & $1.25 \pm 0.29$ & $1.39 \pm 0.19$ \\
\hline UAT & $0.73 \pm 0.25$ & $0.93 \pm 0.39$ & $0.85 \pm 0.35$ & $1.01 \pm 0.51$ \\
\hline
\end{tabular}

the tool damage progression. In CP500 cutting insert, the total growth of $68^{\circ} \mathrm{C}$ was observed at cutting speeds of $700 \mathrm{~s}$ and $10 \mathrm{~m} / \mathrm{min}$ when compared to those obtained at $100 \mathrm{~s}$, whereas, in KC5510, a growth of $42^{\circ} \mathrm{C}$ was noticed at $700 \mathrm{~s}$. Similarly, at a cutting speed of $30 \mathrm{~m} / \mathrm{min}$, the total rise in temperature at $700 \mathrm{~s}$ in CP500 and KC5510 cutting inserts was $44^{\circ} \mathrm{C}$ and $27^{\circ} \mathrm{C}$, respectively, compared to those obtained at $100 \mathrm{~s}$. One of the main disadvantages of the UAT with the studied alloy is the high process zone temperature; however, the rise of average process zone temperature further reduced the yield strength of materials and made it easy for the cutting insert to remove the excessive amount of material with no significant effect on the machined specimen $[14,19]$.

Based on the achieved experimental results, as the machining time increased from $100 \mathrm{~s}$ to $700 \mathrm{~s}$, the growth of the process zone temperature in UAT was higher than that in CT for both of the inserts, leading to its poor life. However, the $6 \%$ cobalt content in the substrate of KC5510 cutting insert increased its toughness, leading to higher tool life in UAT when compared to CP500 cutting inserts.

\subsection{Surface roughness}

Surface quality is measured to be one of the vibrant factors in metal work as it is related directly to fatigue life of most structures [37]. Therefore, the surface topology analysis was carried out for the machined surface using CP500 and KC5510 in both CT and UAT at the studied time intervals. The level of $R a$ observed in CT for CP500 insert was $1.73 \mu \mathrm{m}$, whereas the level of $R a$ at $30 \mathrm{~m} / \mathrm{min}$ was $1.09 \mu \mathrm{m}$. A significant improvement of $36 \%$ in $R a$ was achieved with an increase in the cutting speed from $10 \mathrm{~m} / \mathrm{min}$ to $30 \mathrm{~m} / \mathrm{min}$. Similarly, the levels of $R a$ observed at $10 \mathrm{~m} / \mathrm{min}$ and $30 \mathrm{~m} / \mathrm{min}$ in KC5510 inserts were $1.82 \mu \mathrm{m}$ and $1.02 \mu \mathrm{m}$, respectively.

Further, a momentous decline in $R a$ was noticed in UAT for both inserts, compared to that obtained in CT (see Table 2). The level of $R a$ declined from $1.73 \mu \mathrm{m}$ to $1.01 \mu \mathrm{m}$ in CP500 inserts at a cutting speed of $10 \mathrm{~m} / \mathrm{min}$. Similarly, $24 \%$ improvement in surface roughness was achieved in UAT at a cutting speed of $30 \mathrm{~m} / \mathrm{min}$. Furthermore, the superposition of vibration in cutting direction on KC5510 inserts resulted in improvements of $48 \%$ and $28 \%$ in surface quality at $10 \mathrm{~m} / \mathrm{min}$ and $30 \mathrm{~m} / \mathrm{min}$, respectively. However, the difference in $R a$ levels was found minimal in CP500 and KC5510 cutting inserts due to their similar geometries in both CT and UAT; however, KC5510 inserts comparatively produced better surface finish than CP500 inserts. Degradation in surface quality was observed in CT and UAT for both tools 
with an increase in machining time, as expected [35]. The level of $R a$ at a cutting speed of $10 \mathrm{~m} / \mathrm{min}$ in CT increased from $1.73 \mu \mathrm{m}$ to $1.75 \mu \mathrm{m}$ at $300 \mathrm{~s}$ and, then, reduced slightly to a level of $1.74 \mu \mathrm{m}$ at $500 \mathrm{~s}$. Finally, the level of $R a$ reached $1.80 \mu \mathrm{m}$ at $700 \mathrm{~s}$. Similarly, the levels of $R a$ observed for KC5510 inserts at $300 \mathrm{~s}$, $500 \mathrm{~s}$, and $700 \mathrm{~s}$ were $1.61 \mu \mathrm{m}, 1.79 \mu \mathrm{m}$, and $1.95 \mu \mathrm{m}$, respectively. In this regard, $16 \%$ degradation in surface quality at a cutting speed of $30 \mathrm{~m} / \mathrm{min}$ was achieved in CP500 inserts at $700 \mathrm{~s}$ when compared to the results obtained at $100 \mathrm{~s}$. Similarly, a $26 \%$ increase in $R a$ level was measured in KC5510 inserts at $700 \mathrm{~s}$. The quality of surface finished achieved in CP500 inserts was better than that in CT when compared to the surface finish obtained using KC5510 inserts. The prime reason for better surface quality of CP 500 inserts in $\mathrm{CT}$ is its acceptable performance and better tool life in comparison to KC5510 inserts.

Similarly, $39 \%$ and $34 \%$ degradation rates of surface quality in CP500 and KC5510 inserts, respectively, were measured in UAT at $700 \mathrm{~s}$ at a cutting speed of $10 \mathrm{~m} / \mathrm{min}$ when compared to the surface finish achieved at $100 \mathrm{~s}$. In addition, an increase of $31 \%$ and $27 \%$ in $R a$ level was observed in CP500 and KC5510 insert at $30 \mathrm{~m} / \mathrm{min}$, respectively.

Based on a comparison of the results listed in Table 2, a significant improvement in surface quality was achieved in UAT when compared to CT in different stages of experimentations for both inserts. The improvement of surface roughness was noticeable; besides, the tool life was found poor in UAT for both cutting inserts since they were designed for CT processes.

In a nutshell, the tool life for KC5510 cutting insert was comparatively higher in UAT than that in CP500 inserts, hence better surface finish in UAT in various cutting conditions. Moreover, the level of surface finish obtained in UAT for CP500 cutting inserts was prominently better, compared to the results obtained in CT.

\section{Conclusions}

The main conclusions of this work are:

- A substantial reduction of $70 \%$ in cutting forces was observed in UAT, compared to that in CT at lower cutting speeds;

- A great beneficial effect of vibrations on the machined surface was observed by achieving better surface quality in UAT. The measured level of $R a$ was still lower than $1.6 \mu \mathrm{m}$ in UAT at $700 \mathrm{~s}$;

- The KC5510 cutting inserts yielded comparatively better surface finish in UAT than CP500 due to their enhanced tool life;

- The level of cutting forces observed in UAT with a worn tool was significantly lower than that of forces observed in $\mathrm{CT}$;

- The process zone temperature in UAT for both tools was approximately $34 \%$ higher than that in CT at lower cutting speeds;

- Both inserts demonstrated poor insert life in UAT of Ti-15333 when compared to their performance in $\mathrm{CT}$ in the tested cutting conditions. However, based on the comparative analysis of both inserts and surface quality achieved in the tests, KC5510 is recommended for UAT of Ti-15333.

\section{References}

1. Peters, M. and Leyens, C., Titanium and Titanium Alloys, Wiley-VCH; Germany (2002).

2. Ucun, I., Aslantas, K., and Bedir, F. “An experimental investigation of the effect of coating material on tool wear in micro milling of Inconel 718 super alloy", Wear, 300(1-2), pp. 8-19 (2013).

3. Ávila, R.F., Mancosu, R.D., Machado, A.R., Vecchio, S.D., da Silva, R.B., and Vieira, J.M. "Comparative analysis of wear on PVD TiN and (Ti1-x Alx)N coatings in machining process", Wear, 302(1-2), pp. 1192-1200 (2013).

4. Ezugwu, E., Da Silva, R.B., Bonney, J., and Machado, A.R. "Evaluation of the performance of CBN tools when turning Ti-6Al-4V alloy with high pressure coolant supplies", Int. J. of Mach. Tools and Manuf., 45, pp. 1009-1014 (2005).

5. Özel, T. "Computational modelling of 3D turning: Influence of edge micro-geometry on forces, stresses, friction and tool wear in PcBN tooling", J. of Mater. Proc. Tech., 209, pp. 5167-5177 (2009).

6. Mkaddem, A., Soussia, A.B., and Mansori, M.E. "Wear resistance of CVD and PVD multilayer coatings when dry cutting fiber reinforced polymers (FRP)", Wear, 302(1-2), pp. 946-954 (2013).

7. M'Saoubi, R., Johansson, M.P., and Andersson, J.M., "Wear mechanisms of PVD-coated PCBN cutting tools", Wear, 302(1-2), pp. 1219-1229 (2013).

8. Dhar, N.R., Kishore, S.V.N., Paul, S., and Chattopadhyay, A.B., "The effects of cryogenic cooling on chips and cutting forces in turning AISI 1040 and AISI 4320 steel", J. of Eng. Manuf., 216-part B, pp. 713-724 (2002).

9. Bermingham, M.J., Kirsch, J., Sun, S., Palanisamy, S., and Dargusch, M.S., "New observations on tool life, cutting forces and chip morphology in cryogenic machining Ti-6Al-4V", Int. J. of Mach. Tools and Manuf, 51(6), pp. 500-511 (2011).

10. Dhananchezian, M. and Kumar, P.M. "Cryogenic turning of the Ti-6Al-4V alloy with modified cutting tool inserts", Cryogenics, 51, pp. 34-40 (2011). 
11. Machai, C. and Biermann, D. "Machining of titaniumalloy Ti-10V-2Fe-3Al under cryogenic conditions: cooling with carbon dioxide snow", J. of Mater. Proc. Tech, 211, pp. 1175-1183 (2011).

12. Wang, Z.Y., Rajurkar, K.P., Fan, J., Lei, S., Shin, Y.C., and Petrescu, G. "Hybrid machining of Inconel 718", Int. J. of Mach. Tools and Manuf, 43(13), pp. 1391-1396 (2003).

13. Dandekar, C.R., Shin, Y.C., and Barnes, J. "Machinability improvement of titanium alloy (Ti-6Al-4V) via LAM and hybrid machining", Int. J. of Mach. Tools and Manuf, 50(2), pp. 174-182 (2010).

14. Muhammad, R., Maurotto, A., Demiral, M., Roy, A., and Silberschmidt, V.V. "Thermally enhanced ultrasonically assisted machining of Ti alloy", CIRP J. of Manuf. Sci. and Tech, 7(2), pp. 159-167 (2014).

15. Muhammad, R., Hussain, M.S., Maurotto, A., Siemers, C., Roy, A., and Silberschmidt, V.V. "Analysis of a free machining $\alpha+\beta$ titanium alloy using conventional and ultrasonically assisted turning", $J$. of Mater. Proc. Tech, 214(4), pp. 906-915 (2014).

16. Maurotto, A., Siemers, C., Muhammad, R., Roy, A., and Silberschmidt, V.V. "Ti alloy with enhanced machinability in UAT turning", Metall. and Mater. Trans. A, 45(6), pp. 2768-2775 (2014).

17. Muhammad, R., Roy, A., and Silberschmidt, V.V. "Finite element modelling of conventional and hybrid oblique turning processes of titanium alloy", Proc. CIRP, 8, pp. 509-514 (2013).

18. Muhammad, R., Demiral, M., Roy, A., and Silberschmidt, V.V. "Modelling the dynamic behaviour of hard-to-cut alloys under conditions of vibro-impact cutting", J. of Phy.: Conf. Ser., 451, pp. 1-11 (2013).

19. Maurotto, A., Muhammad, R., Roy, A., and Silberschmidt, V.V. "Enhanced ultrasonically assisted turning of a $\beta$-Titanium alloy", Ultrasonics, 53(7), pp. 1242-1250 (2013).

20. Nategh, M.J., Razavi, H., and Abdullah, A. "Analytical modeling and experimental investigation of ultrasonic-vibration assisted oblique turning, part I: Kinematics analysis", Int. J. of Mech. Sci., 63(1), pp. 1-11 (2012).

21. Muhammad, R., Maurotto, A., Roy, A., and Silberschmidt, V.V. "Ultrasonically assisted turning of Ti6Al-2Sn-4Zr-6Mo", J. of Phy.: Conf. Ser., 382, pp. 1-12 (2012).

22. Muhammad, R., Ahmed, N., Roy, A., and Silberschmidt, V.V. "Turning of advanced alloys with vibrating cutting tool", Solid State Phenom., 188, pp. 277-284 (2012).

23. Muhammad, R., Ahmed, N., Roy, A., and Silberschmidt, V.V. "Numerical modelling of vibrationassisted turning of Ti-15333", Proc. CIRP, 1, pp. 347352 (2012).
24. Maurotto, A., Muhammad, R., Roy, A., Babitsky, V.I., and Silberschmidt, V.V. "Comparing machinability of Ti-15-3-3-3 and Ni-625 alloys in UAT", Proc. CIRP, 1, pp. $330-335$ (2012).

25. Mitrofanov, A.V., Babitsky, V.I., and Silberschmidt, V.V. "Thermomechanical finite element simulations of ultrasonically assisted turning", Comput. Mater. Sci., 32, pp. 463-471 (2005).

26. Sharman, A., Bowen, P., Aspinwall, D., and Dewes, C., Ultrasonic Assisted Turning of Gamma Titanium Aluminide, Rolls-Royce PLC (2001).

27. Kumabe, J., Fuchizawa, K., Soutome, T., and Nishimoto, Y. "Ultrasonic superposition vibration cutting of ceramics", Prec. Eng., 11(2) pp. 71-77 (1989).

28. Ahmed, N., Mitrofanov, A.V., Babitsky, V.I., and Silberschmidt, V.V. "Stresses in ultrasonically assisted turning", App. Mech. and Mater., 5, pp. 351-358 (2006).

29. Muhammad, R., Maurotto, A., Roy, A., and Silberschmidt, V.V. "Hot ultrasonically assisted turning of $\beta$-Ti alloy", Proc. CIRP, 1, pp. 336-341 (2012).

30. Muhammad, R., Maurotto, A., Roy, A., and Silberschmidt, V.V. "Analysis of forces in vibro-impact and hot vibro-impact turning of advanced alloys", App. Mech. and Mater., 70, pp. 315-320 (2011).

31. Muhammad, R., Ahmed, N., Ullah, H., Roy, A., and Silberschmidt, V.V. "Hybrid machining process: Experimental and numerical analysis of hot ultrasonically assisted turning", Int. J. Adv. Manuf. Tech., 97, pp. 2173-2192 (2018).

32. Muhammad, R., Ahmed, N. Ullah, H., and Silberschmidt, V.V. "Dynamic behaviour of $\beta$-Ti-15333 in ultrasonically assisted turning: Experimental and numerical analysis", Scientia Iranica, Transac. B: Mech. Engg, 24(6), pp. 2904-2914 (2017).

33. Exner, H.E. and Gurland, J.A. "A review of parameters influencing some mechanical properties of tungsten carbide cobalt alloys", Powd. Metall., 13, pp. 13-31 (1970).

34. Mills, B. and Redford, A.H. Machinability of Engineering Materials, London; New York, Applied Science Publishers (1983).

35. Muhammad, R, Mistry, A, Khan, S. W, Ahmed, N., Roy, A., and Silberschmidt, V. V., "Analysis of tool wear in ultrasonically assisted turning of $\beta$-Ti$15 \mathrm{~V}-3 \mathrm{Al}-3 \mathrm{Cr}-3 \mathrm{Sn}$ alloy" Scientia Iranica, Transac. B: Mech. Engg., 23(4), pp. 1800-1810 (2016).

36. Komanduri, R. and Hou, Z.B. "On thermoplastic shear instability in the machining of a titanium alloy (Ti-6Al4V)", Metall. and Mater. Trans. A, 33(9), pp. 29953010 (2002).

37. Ulutan, D. and Ozel, T. "Machining induced surface integrity in titanium and nickel alloys: A review", Int. J. of Mach. Tools and Manuf, 51(3), pp. 250-280 (2011). 


\section{Biographies}

Riaz Muhammad graduated in Mechanical Engineering with distinction from UET Peshawar, Pakistan, in 2006 followed by his MS and PhD degrees in Mechanical Engineering from Ghulam Ishaq Khan Institute of Science and Technology (GIKI) and Loughborough University in 2009 and 2013, respectively. $\mathrm{He}$ is currently working as an Assistant Professor in Mechanical Engineering Department, University of Bahrain, Bahrain. His research activities include finite element modelling, hybrid machining process, industry 4.0, product design and development, composite, polymers and biomedical materials.

Naseer Ahmed received BS and MS degrees in Mechanical Engineering from UET Peshawar and GIKI, respectively. He received his $\mathrm{PhD}$ degree form Loughborough University, UK in 2007. He is Professor of Manufacturing at CECOS University, Pakistan, heads mechanics of advanced materials and manufacturing research group (AM2RG) and Director of research and development. His research activities include, manufacturing, biomedical materials, composite materials and assisted machining processes.

Shahid Maqsood is currently working as an Associate Professor in the Industrial Engineering Department, UET Peshawar, Jalozai Campus, Pakistan. He received his BSc degree in Mechanical Engineering from UET Peshawar and his MS degree in in the same field from Ghulam Ishaq Khan Institute of Engineering Sciences and Technology, Topi, Swabi, Pakistan in 2003. His research expertise are in the field of manufacturing processes, machining, industrial process optimization, and stochastic analysis.

Khurshid Alam is Assistant Professor in the Department of Mechanical and Industrial Engineering, Sultan Qaboos University, Sultanate of Oman. He received his
PhD degree in Mechanical Engineering from Wolfson School of Mechanical and Manufacturing Engineering, Loughborough University, UK, his BEng degree in the same field from University of Engineering and Technology, Peshawar, Pakistan, and his MSc degree in Design and Manufacturing from GIK Institute of Engineering Sciences and Technology, Topi, Pakistan. His current research is focused on the experimental measurements and computational analysis of bone cutting forces in conventional and vibrational mode. His other areas of research are experimental and computational modeling and analysis of biomechanical components and systems.

Muftooh Ur Rehman received his BSc degree in Mechanical Engineering from UET Peshawar, his MS degree in Mechanical Engineering from GIKI, Pakistan in 2010, his PhD degree from University of Strathclyde, United Kingdom, in 2016 in incremental sheet forming of advanced alloys. His research interest includes digital manufacturing, sustainable manufacturing, industry 4.0, industrial robotics, product development, manufacturing, material testing and management through modelling and simulation, design and analysis (FEA and $\mathrm{CFD}$ ), and experimental validation.

Vadim V. Silberschmidt educated at Perm Technical University (USSR). He heads the Mechanics of Advanced Materials Research Group with $30+$ members. He is a Charted Engineer, Fellow of the Institution of Mechanical Engineering and Institute of Physics. He is Editor-in-Chief of Mechanics of Advanced Materials and Modern Processes, Associate Editor of Journal of Engineering Materials and Technology. His research activities include multi-scale models of damage and fracture evolution in microstructured materials, finiteelement analysis of complex deformational behaviour, damage and fracture of advanced materials under various loading conditions, impact fatigue, mechanics of composites and nano-composites, Mechanics. 